\title{
Plant growth promotion using microbial IAA producers in conjunction with azolla: a novel approach
}

V. Raut ${ }^{1,5}$, I. Shaikh ${ }^{1,5}$, B. Naphade ${ }^{2,5}$, K. Prashar ${ }^{3,5}$ and N. Adhapure ${ }^{4,5^{*}}$

\begin{abstract}
Studies were conducted to find efficient Indole acetic acid producing strains and assessing the effectiveness of combined dose of azolla (dried) and IAA producers on plant growth. Out of ten isolates, only two isolates, viz, F1 and $\mathrm{G} 2$ were found to be potent IAA producers and were used for further experiments. It was found that the isolate F1 and $\mathrm{G} 2$ produced maximum amount of IAA at $0.9 \%$ tryptophan and incubation for $72 \mathrm{~h}$ at room temperature. The optimum $\mathrm{pH}$ for IAA production for isolates $\mathrm{F} 1$ and $\mathrm{G} 2$ was found to be at $\mathrm{pH}$ 9. The isolates were also assessed for the presence of other plant growth promoting activity, such as hydrogen cyanide production, oxalate solubilization, phosphate solubilization and zinc solubilization. Effect of IAA producers on seed germination was done by pot experiments carried out into sets. Isolates F1 and G2 were found efficient for plant growth promotion in desired aspects. Effect of combined dose of azolla and IAA producers on seed germination was assessed by pot experiments. For this, dried powder of azolla was added during sowing of culture treated seeds. No further culture supply was given to the seeds. Azolla has high protein content. Slow protein releasing property of azolla can be useful to provide constant supply of the precursor (tryptophan) for IAA synthesis by isolate. In addition to the plant exudates, azolla may also give constant supply of tryptophan. From all the assessed samples, the isolates Fl and G2 showed efficient growth of plants in all aspects. G2 was found to be more potent than F1. So as to assess the compatibility of isolate in natural conditions, field studies were done. Four plots designed having individual size $9 \times 5 \mathrm{~m}$, were used. It was found that plots 3 (only culture) and 4 (culture with azolla) showed better plant growth as compared to others. On the basis of IAA producing ability of G2, pot experiments and field studies, it was concluded that isolate G2 can be used alone or in conjunction with azolla as a biofertilizer to get better plant growth.
\end{abstract}

\section{Background}

Rhizosphere supports large and active microbial population capable of exerting beneficial, neutral and detrimental effect on the plants. As plant roots grow through soil, they release water-soluble compounds such as amino acids, sugars and organic acids that supply food for the microorganisms. In return the microorganisms provide nutrients for the plants. All this activity makes the rhizosphere, the most dynamic environment in soil [1]. The plant-microbe interaction in the rhizosphere is responsible for increasing plant health and soil fertility [2].

\footnotetext{
*Correspondence: adhapurenn@gmail.com

${ }^{4}$ Department of Biotechnology and Microbiology, Vivekanand Arts Sardar Dalipsingh Commerce and Science College, Aurangabad, MS, India Full list of author information is available at the end of the article
}

Plant growth promoting rhizobacteria are a group of free living soil bacteria, which have the ability to promote growth and yield of crop plant by direct and indirect mechanism [3]. Phytohormones play an important role as signals and regulators of growth and development in plants. Auxins, among them in particular, indole-3-acetic acid (IAA), are the most studied plant growth regulators, and this includes physiological, biochemical and genetic aspects [4].

Indole acetic acid (IAA) is a natural auxin which is also synthesized in many species of non-seeded plants, many bacteria, fungi and algae. The amino acid tryptophan is commonly regarded as the precursor for the biosynthesis of auxin in plants [5]. Therefore, screening of bacteria for their, in vitro potential of auxin production could provide 
a reliable base for selection of effective plant growth promoting bacteria.

The production and concentration of IAA could also have influenced by other factors besides species or strain of rhizobacteria such as PSB and medium conditions, growth stage and availability of substrates [6]. In the presence of Trp microbes release greater quantities of IAA [7, $8,9]$ ), and other related compounds like gibberellins and cytokinins $[9,10]$.

Azolla is a genus of heterosporous aquatic fern which contains within the leaf cavities the N2-fixing cyanobacterium Anabaena azollae. The host Azolla synthesizes and provides photosynthates essential for the nitrogenase activity of the cyanobiont, while A. azollae supplies fixed nitrogen to the fern [11]. The cyanobacterial strains belonging to the genera Nostoc and Anabaena comprised $80 \%$ of the rhizosphere isolates, which were also efficient in enhancing the germination and growth of wheat seeds and exhibited significantly high protein accumulation and IAA production [12]. In addition to its influence on soils physical properties, azolla is important in the cycling of nutrients. When the azolla is incorporated into the soil and humus is formed, these nutrients are slowly released into the soil as decomposition progresses. Even though azolla appears to be a rather delicate plant that would rapidly decompose, it actually takes six weeks or more for most of the nutrients to be released because the plant has rather high lignin content. Slow decomposition gives a natural slow release effect that is ideal for efficient absorption of the nutrients released. Another factor in azolla effectiveness as a green manure is its low carbon to nitrogen ratio of about 10:1. This high ratio ensures that azolla nitrogen will not be tied up by bacteria that are involved in decomposition of an overabundance of carbonaceous plant residues [13]. Nitrogen compounds released include small amounts of amide, peptides, and free amino acids, with most as nitrate and ammonium. Released $\mathrm{N}$ is readily taken up by surrounding organisms, including vascular plants, fungi, actinomycetes, and bacteria [14].

There are three primary methods for applying Azolla to crops. First, it may be grown in the field as a monocrop during the fallow season and then incorporated into the soil before planting the target crop. Second, Azolla may be grown as an intercrop among the target crop. Third, natural or deliberately cultured growths of Azolla may be harvested from ponds, swamps, or flooded fields and applied to a variety of target crops, either by incorporating it into the soft before planting the crop or by applying it as much on top of the soil around the bases of crop plants. Often, a combination of these methods of application is utilized [15].
As we know, IAA should be supplied in optimum amount to plants. Using only IAA producers at the time of sowing cannot guarantee the production of IAA as it is tryptophan limiting. Natural source for tryptophan is the exudates from plants. The carbonaceous compounds released through root exudates includes sugars, polysaccharides, amino acids, aromatic acids, aliphatic acids, fatty acids, sterols, phenolics, enzymes, proteins, plant growth regulators and secondary metabolites. Secondary metabolites such as flavonoids of plants are released during seed germination [16]. In this study, azolla has been applied in conjunction with IAA producers, considering that slow nutrient release property of azolla could be a source of controlled tryptophan supply to IAA producers.

Today, biofertilizers have emerged as a highly potent alternative to chemical fertilizers due to their ecofriendly, easy to apply, non-toxic and cost effective nature. Also, they make nutrients that are naturally abundant in soil or atmosphere, usable for plants and act as supplements to agrochemicals. Biofertilizer is a substance which contains living microorganisms which when applied to seed, plant surfaces, or soil colonizes the rhizosphere or the interior of the plant and promotes growth by increasing the availability of primary nutrients to the host plant [17]. Assuming all the above parameters a better approach of using Azolla and IAA producing microorganisms as biofertilizer was proposed and the studies were carried out accordingly.

\section{Methods}

\section{Collection of soil sample}

Soil samples were collected from three locations, viz. Garden soil (rhizospheric soil sample) GS, Farm soil (non-rhizospheric soil sample) FS and College campus soil (non rhizospheric soil sample) CS. Non rhizospheric soil sample was basically a soil from a ploughed farm. This was taken for getting the natural/robust microbial flora from a farm soil. Rhizospheric soil samples were actually taken from the rhizosphere of garden plants. This was done for getting maximum IAA producers as they are present in such environment. The purpose of taking rhizospheric and non-rhizospheric soil sample was to assess the diverse microflora for the said IAA producing activity. All samples were collected in sterile containers. The soil was then crushed in sterile mortar and pestle aseptically to get a fine powder and this powdered soil was then used for further experiments.

\section{Enrichment of IAA producing bacteria}

Five gram of each soil sample was inoculated in $100 \mathrm{ml}$ conical flask containing sterile nutrient broth (NB) supplemented with $0.1 \%$ of tryptophan [18]. The flaks were 
labeled as, GS, FS and CS for garden soil, farm soil and college campus soil, respectively.

The flasks were kept for enrichment by incubating at room temperature for $24 \mathrm{~h}$. IAA was determined in vitro by the method of Salkowski [18]. From each of the enriched flasks, $1.5 \mathrm{ml}$ of culture was taken in centrifuge tube and centrifuged for $5 \mathrm{~min}$ at $8000 \mathrm{rpm}, 1 \mathrm{ml}$ of supernatant was taken and mixed with $3 \mathrm{ml}$ of Salkowski's reagent and incubated for $30 \mathrm{~min}$ in dark for development of pink color. Spectrophotometric analysis of each sample was done for IAA detection. The soil samples, which showed higher absorbance at $520 \mathrm{~nm}$ were considered as efficient IAA producers and chosen for further experimental procedure.

\section{Isolation of bacterial isolates for IAA production}

From the selected flasks (FS and GS), loopful of cultures were streaked on two sterile (N.A $+0.1 \%$ tryptophan) plates separately, and incubated for $24 \mathrm{~h}$ at room temperature for obtaining isolated colonies.

\section{Screening for IAA producing microorganisms}

After incubation, ten different colonies were selected (five colonies from each plate) and were labeled according to their source, viz. For FS sample isolates: F1, F2, F3, F4, and F5 and for GS sample isolates: G1, G2, G3, G4, and G5. These isolated colonies were inoculated in sterile $10 \mathrm{ml}(\mathrm{NB}+0.1 \%$ tryptophan) tubes separately and incubated at room temperature for $24 \mathrm{~h}$.

Simultaneously, $1 \mathrm{ml}$ of culture from each flask (FS and GS) was added in flask containing $25 \mathrm{ml}$ sterile $(\mathrm{NB}+0.1 \%$ tryptophan) medium separately and were labeled as consortiums, viz. FC (Farm soil consortium) GC (Garden soil consortium). These flasks were then incubated at room temperature for $24 \mathrm{~h}$.

After incubation, $1.5 \mathrm{ml}$ broth from each tube and flask were taken in respective centrifuge tubes and centrifuged at $8000 \mathrm{rpm}$ for $5 \mathrm{~min}$. $1 \mathrm{ml}$ of supernatant from each tube was mixed with $3 \mathrm{ml}$ of Salkowski's reagent and the tubes were incubated at room temperature in dark for 30 min and observed for pink color development [19]. Optical densities of all these samples were taken at $520 \mathrm{~nm}$ and their IAA concentrations were measured according to standard graph values. The isolates, which showed maximum IAA concentration were selected for further experiments.

\section{Effect of different factors on IAA production Effect of tryptophan concentration}

Two hundred milliliter of sterile NB was distributed in 20 sterile test tubes. The tubes were supplemented with varying concentration of tryptophan, viz. $0.1,0.3,0.5,0.7$ and $0.9 \%$ (four tubes each with same tryptophan concentration). Then the tubes were inoculated with isolates (F1 and G2) and consortiums (FC and GC) for different incubation periods, i.e., 24, 48, 72 , and $96 \mathrm{~h}$, respectively, and the tubes were assessed for IAA concentration by Salkowski's method after each $24 \mathrm{~h}$.

\section{Effect of $p H$}

One hundred and sixty milliliter of sterile (NB $+0.1 \%$ tryptophan) was prepared and distributed in 16 sterile test tubes with $\mathrm{pH} 5,7,9$ and 11 (4 tubes each with same $\mathrm{pH}$ ), respectively. The tubes prepared according to respective $\mathrm{pH}$ were inoculated with isolates and consortium and labeled according to culture inoculated and kept for incubation at room temperature for $24,48,72$, and $96 \mathrm{~h}$. All the incubated samples were assessed for measuring IAA concentration by Salkowski's method after each $24 \mathrm{~h}$.

\section{Assessment of other plant growth promoting activities of the isolates Hydrogen cyanide production}

Isolates (F1 and G2) and consortiums (FC and GC) were tested for the production of $\mathrm{HCN}$ by spreading them on sterile N.A plate amended with $0.44 \%$ of glycine. A circular disk of Whatman's filter paper No. 1 of $10 \mathrm{~cm}$ diameter was soaked in $2 \%$ sodium carbonate in $0.5 \%$ picric acid solution and placed in the lid of the plates [20]. One plate was uninoculated and kept as control. Plates were sealed with para film and incubated at room temperature for $24 \mathrm{~h}$. After incubation the plates were observed for the development of yellow to light brown, moderate brown or strong brown color on filter paper by referring the control plate.

\section{Oxalate solubilization}

The agar plates containing oxalic acid degradation medium were prepared according to the method of Dickman and Mitra [21], all the samples (isolates and consortiums) were spotted on the respective plates and one plate was kept uninoculated which was referred as control. The plates were incubated at room temperature for 7 days. After incubation the plates were observed for formation of clear halo around the bacterial spots.

\section{Phosphate solubilization}

Evaluation of tricalcium phosphate solubilization of isolates (F1 and G2) and consortiums (FC and GC) was assessed using Pikovskaya's agar. Each bacterial culture was spot-inoculated in the centre of the plate [22]. After incubation for $48 \mathrm{~h}$ at room temperature, each plate was observed for zone of clearance, for the indication of inorganic phosphate solubilization [23]. 


\section{Zinc solubilization}

Zinc solubilization ability of the isolates (F1 and G2) and consortiums (FC and GC) were detected by spotting the log phase culture of bacterial strains on Tris-minimal medium plates having zinc phosphate, and zinc carbonate as source of insoluble inorganic zinc [20]. The inoculated plates were then incubated at room temperature for 3 days, and observed for the clearing zone around the colonies (due to the solubilization of inorganic zinc by bacteria).

\section{Biochemical characterization}

Biochemical studies were carried out for the identification of isolates (F1 and G2) as follows: Catalase test, Methyl-Red Test, Voges-Proskauer Test, Citrate Utilization Test, Phenylalanine Deamination Test, Urea Hydrolysis Test, Starch Hydrolysis Test, Casein Hydrolysis Test, Triple Sugar Iron (TSI) test, catalase, oxidase, urease and sugar fermentation tests.

\section{Pot experiment 1: effect of IAA producer on plant growth} Ten pots of equal size and volume were taken. The pots were equally distributed in two batches ( 5 pots in each batch). The pots were filled with sterile soil and wetted with sterile distilled water. The seeds of soyabean were selected for sowing in pots of both the batches. Prior to sowing, the seeds were surface sterilized by washing under tap water and placed in beaker containing distilled water. A Pinch of SDS was added and seeds were shaken gently for 1-2 min. The water was discarded and $70 \%$ ethanol was added for 1-2 min. Ethanol was discarded and seeds were placed in sterile distilled water, a pinch of $\mathrm{HgCl}_{2}$ was added and kept for $15 \mathrm{~min}$. Further 3-4 washes of distilled water were given and all the water was discarded. After surface sterilization the seeds were treated with cultures, F1, G2 and FC, GC respectively.

The pots were labeled according to the cultures by which they were treated. One pot was sown with culture untreated seeds and kept as control. For batch 2, similar procedure was followed as of batch 1 , but pots were supplied continuously with their respective cultures at interval of $24 \mathrm{~h}$. Both the batches were supplied with sterile distilled water at every $24 \mathrm{~h}$ till 1 month and observed for growth of plantlets. After 1 month the plantlets were gently removed from pots by immersing them in water as to remove the soil. The plants of both the batches were assessed for root length, shoot length, primary-secondary leaves and chlorophyll content.

\section{Root length measurement}

All the plantlets of batch 1 and batch 2 were removed gently from pots and each root of each plantlet was measured manually using scale. The average root measurement for each pot of both the batches was calculated.

\section{Shoot length measurement}

The shoots of all the plantlets of both the batches were excised and measured manually using scale.

\section{Primary and secondary leaves counting}

The leaves of each plantlet were counted manually and noted according to their nature (i.e., primary and secondary).

\section{Measuring chlorophyll content}

From both the batches, one plantlet from each pot was taken as a sample for assessing the chlorophyll content. From each of the selected plant $1 \mathrm{gm}$ of finely cut well mixed leaf tissue was taken in clean mortar. Tissue was ground to fine pulp with the addition of $20 \mathrm{ml}$ of $80 \%$ acetone. Centrifuged ( $5000 \mathrm{rpm}$ for $5 \mathrm{~min}$ ) and transferred supernatant to volumetric flask. Residual tissue was ground again with $20 \mathrm{ml}$ of $80 \%$ acetone, centrifuged and the supernatant was transferred to a $100 \mathrm{ml}$ volumetric flask. This procedure was repeated until the residue became colorless. Mortar and pestle was thoroughly washed with $80 \%$ acetone and the clear washings were collected in $100 \mathrm{ml}$ volumetric flask. Volume was made up to $100 \mathrm{ml}$ with $80 \%$ acetone. Absorbance of solutions was read at $645 \mathrm{~nm}, 663 \mathrm{~nm}$ against the solvent ( $80 \%$ acetone) blank. Following formula was used for determination of chlorophyll A and B.

$$
\begin{aligned}
\mathrm{Mg} \text { chlorophyll A/g tissue }= & 12.7\left(\mathrm{~A}_{663}\right)-2.69\left(\mathrm{~A}_{645}\right) \\
& \times \mathrm{V} / 1000 \times \mathrm{W}
\end{aligned}
$$

$\mathrm{Mg}$ chlorophyll $\mathrm{B} / \mathrm{g}$ tissue $=22.9\left(\mathrm{~A}_{645}\right)-4.68\left(\mathrm{~A}_{663}\right)$

$$
\times \mathrm{V} / 1000 \times \mathrm{W}
$$

where, $\mathrm{A}=$ absorbance at specific wavelength, $\mathrm{V}=$ final volume of chlorophyll extract in $80 \%$ of acetone, $\mathrm{W}=$ fresh weight of tissue extracted

\section{Cultivation of Azolla}

For cultivating azolla, a pit of size $7 \times 4$ feet and of depth $20 \mathrm{~cm}$ was created by arranging bricks and placing plastic mat over the bricks for water holding. The pit was built under shade. A pit can also be done on ground by digging and placing plastic mat in it. The pit was filled with water up to the edge of the pit and soil mixed with cattle manure which was added to the pit as per requirement. The azolla culture was brought form Krishi Vidnyan Kendra, Kharpudi, Jalna. The azolla culture was inoculated in the prepared pit and kept for growth. After sufficient amount of growth, azolla was taken from the pit, dried 
and powdered, which was used for pot experiment 2 and field studies.

\section{Pot experiment 2: effect of co inoculation of IAA producer and azolla on plant growth}

For this experiment, six pots of equal size and volume were taken. The pots were filled with sterile soil and wetted with sterile distilled water. Prior to sowing, the seeds were surface sterilized as described in pot experiment 1 and treated with our sample cultures, respectively. At the time of sowing a pinch of azolla powder was added with each seed. In the remaining two pots, Seeds in one pot were sown only with azolla powder without treating it by sample cultures and the other pot was kept blank with no treatment of azolla powder and sample cultures which was kept as control. All the samples were labeled according to their sample cultures (i.e., F1, G2 and FC, GC, respectively). Both the batches were supplied with sterile distilled water at every $24 \mathrm{~h}$ till one month and observed for growth of plantlets. After one month the plantlets were gently removed from pots by immersing them in water as to remove the soil. The plants were assessed for root length, shoot length, primary-secondary leaves and chlorophyll content. This was done using the procedure followed in pot experiment 1 .

\section{Field study: effect of co inoculation of IAA producer and azolla on plant growth}

From the results of pot experiments 1 and 2, the isolate $\mathrm{G} 2$ found to be most efficient among all the samples and chosen for this experiment. In the selected field, four plots of equal size $(9 \times 5 \mathrm{~m})$ were selected for the experiment. In each plot, 15 rows were created manually for sowing of seeds and draining water from the spaces of adjacent rows. Seeds were sown near the bottom of rows to get access of water draining through it. Soyabean seeds were selected for sowing. The four plots were labeled as 1, 2, 3 and 4. In plot 1, seeds were sown without treating with culture and azolla powder and kept as control. Seeds of plot 2 were sown only with azolla powder without treating with culture. Plot 3 consisted with seeds sown by treating only with culture. In plot 4, seeds were sown with culture treatment and supplement of azolla powder. Supply of water was given to each plot, at the interval of every 2-3 days for one month and observed for plant growth. After a month, one plant from each plot was selected for assessing root length; shoot length, primary-secondary leaves and chlorophyll content. The selection of plant, for the assessment of above parameters was selected on the majority of maximum shoot length among all the plants of each plot. The assessment of above parameters was done using the same procedures as followed in pot experiments 1 and 2 .

\section{Results \\ Enrichment of IAA producing bacteria}

After assessing using Salkowski's reagent, it was found that among all three enriched soil samples, two samples, viz. FS and GS showed formation of pink color with high intensity than CS. So, for screening of IAA producers only GS and FS were used and not the CS.

\section{Screening of bacterial isolates for IAA production}

The assessment of all the ten isolates (F1, F2, F3, F4, F5 and G1, G2, G3, G4, G5) by Salkowski's method, it was found that, among all the samples, F1 and G2 showed maximum absorbance for IAA at $520 \mathrm{~nm}$. GC and FC also showed good IAA production.

\section{Effect of different factors on IAA production Effect of tryptophan concentration on IAA production}

The samples inoculated with varying concentration of tryptophan, viz. $0.1,0.3,0.5,0.7$ and $0.9 \%$ in NB medium, showed gradual increase in production of IAA with the increase of tryptophan concentration and incubation period. The samples were assessed by Salkowski's method. The isolates (F1 and G2) showed maximum IAA production at $0.9 \%$ concentration of tryptophan and incubation of $72 \mathrm{~h}$, whereas maximum IAA productivity of consortiums (FC and GC) was also observed at $0.9 \%$ concentration of tryptophan but by incubating for $96 \mathrm{~h}$. The OD values and concentration of IAA produced by all the samples with respect to varying concentration of tryptophan and incubation periods, is represented in Table 1 and Figs. 1 and 2.

\section{Effect of $\mathrm{pH}$ on IAA production}

All the samples inoculated in the $\mathrm{NB}+0.1 \%$ tryptophan) medium containing varying $\mathrm{pH}$, viz. 5, 7, 9 and 11 showed different concentration of IAA production at different incubation periods. After assessing the samples by Salkowski's method, it was observed that F1 and G2 showed maximum IAA production at $\mathrm{pH} 9$ but at different incubation periods, i.e., 24 and $72 \mathrm{~h}$. The consortium FC showed maximum IAA productivity at $\mathrm{pH} 9$ and incubation at $48 \mathrm{~h}$, whereas GC showed maximum IAA production at $\mathrm{pH} 11$ and incubation at $72 \mathrm{~h}$. The OD values and concentration of IAA produced by all the samples with respect to varying $\mathrm{pH}$ and incubation periods, is represented in Table 2 and Fig. 3.

IAA production abilities of all four cultures at $\mathrm{pH} 9.0$ was assessed using one way ANOVA and it was found that at 0.05 level the means are significantly different $(F=120.52152, p=5.3568)$ 
Table 1 Effects of tryptophan concentration on IAA production

\begin{tabular}{|c|c|c|c|c|c|}
\hline \multirow{2}{*}{$\begin{array}{l}\text { Culture } \\
\text { samples }\end{array}$} & \multirow{2}{*}{$\begin{array}{l}\text { Tryptophan } \\
\text { concentration (\%) }\end{array}$} & \multicolumn{4}{|c|}{ Concentration of IAA $(\mu \mathrm{g} / \mathrm{ml})$} \\
\hline & & $24 \mathrm{~h}$ & $48 \mathrm{~h}$ & $72 \mathrm{~h}$ & $96 \mathrm{~h}$ \\
\hline \multirow[t]{5}{*}{$\mathrm{F} 1$} & 0.1 & $9.5( \pm 0.4)$ & $9( \pm 0.4)$ & $11.6(0.8)$ & $10.1( \pm 0.4)$ \\
\hline & 0.3 & $10.4( \pm 0.4)$ & $17.8(0.8)$ & $18.1( \pm 0.8)$ & $16(0.8)$ \\
\hline & 0.5 & $16.4( \pm 0.4)$ & $21( \pm 1.2)$ & $25( \pm 1.6)$ & $22.6( \pm 1.2)$ \\
\hline & 0.7 & $10.4( \pm 0.4)$ & $30.1( \pm 1.5)$ & $30.2( \pm 1.6)$ & $28( \pm 1.6)$ \\
\hline & 0.9 & $21.5( \pm 1.2)$ & $27( \pm 1.6)$ & $32.5( \pm 1.5)$ & $30.1( \pm 1.2)$ \\
\hline \multirow[t]{5}{*}{ G2 } & 0.1 & $10.1( \pm 0.4)$ & $16(0.8)$ & $19( \pm 0.8)$ & $17.3(0.8)$ \\
\hline & 0.3 & $15.1( \pm 0.8)$ & $27.5( \pm 1.4)$ & $27.7( \pm 1.8)$ & $30( \pm 1.6)$ \\
\hline & 0.5 & $19( \pm 0.8)$ & $30.1( \pm 1.6)$ & $40( \pm 2.2)$ & $39( \pm 2.1)$ \\
\hline & 0.7 & $25.5( \pm 1.6)$ & $38.5( \pm 2.0)$ & $37.7( \pm 2.1)$ & $43( \pm 2.1)$ \\
\hline & 0.9 & $23( \pm 1.2)$ & $39.5( \pm 2.1)$ & $47(2.3)$ & $34(1.6)$ \\
\hline \multirow[t]{5}{*}{ FC } & 0.1 & $5.5( \pm 0.4)$ & $10( \pm 0.4)$ & $10.4( \pm 0.4)$ & $9.2( \pm 0.4)$ \\
\hline & 0.3 & $9.5( \pm 0.4)$ & $5.7( \pm 0.4)$ & $25.5( \pm 1.6)$ & $25.6( \pm 1.6)$ \\
\hline & 0.5 & $10.9( \pm 0.4)$ & $21.5( \pm 1.2)$ & $30( \pm 1.6)$ & $32( \pm 1.4)$ \\
\hline & 0.7 & $14.5( \pm 0.5)$ & $25.5( \pm 1.6)$ & $40( \pm 2.1)$ & $43.5( \pm 2.1)$ \\
\hline & 0.9 & $14.2( \pm 0.5)$ & $31(1.7)$ & $42.5(2)$ & $47.5(2.0)$ \\
\hline \multirow[t]{5}{*}{ GC } & 0.1 & $2.5( \pm 0.4)$ & $1.6( \pm 0.4)$ & $6.5( \pm 0.4)$ & $6.2( \pm 0.4)$ \\
\hline & 0.3 & $3( \pm 0.4)$ & $6( \pm 0.5)$ & $13.6(0.8)$ & $13.2(0.8)$ \\
\hline & 0.5 & $2.4( \pm 0.4)$ & $6.6( \pm 0.5)$ & $17.7( \pm 0.8)$ & $19.5( \pm 0.8)$ \\
\hline & 0.7 & $4.9( \pm 0.4)$ & $13.5(0.8)$ & $20( \pm 1.0)$ & $22( \pm 1.2)$ \\
\hline & 0.9 & $4.1(0.6)$ & $16.9(0.8)$ & $22.5(1.4)$ & $26(1.0)$ \\
\hline
\end{tabular}

The IAA producing ability of all four cultures at $72 \mathrm{~h}$ with $0.9 \%$ tryptophan concentration was assessed by One way ANOVA and found that at 0.05 level the means are significantly different $(F=106.60588, p=8.64269)$

Experiments were done in triplicates $\pm S D$

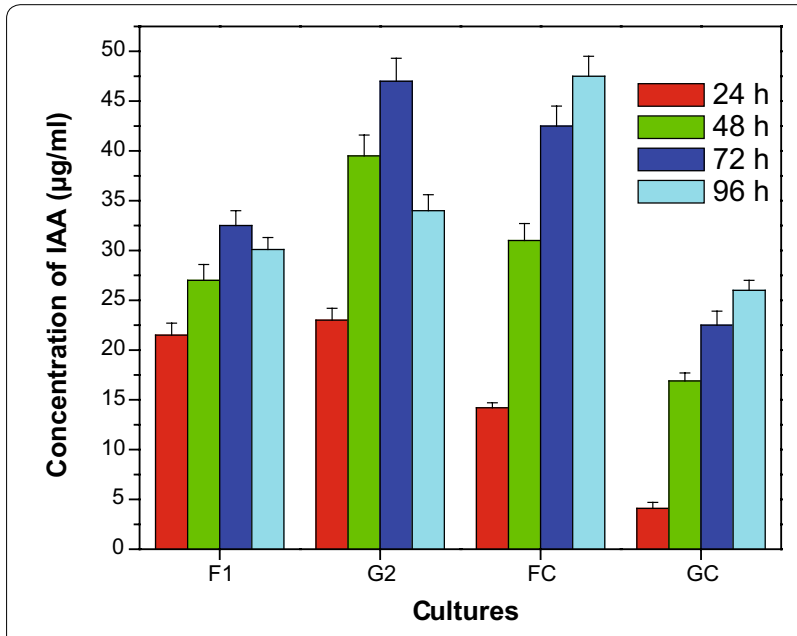

Fig. 1 Efficiency of cultures to produce IAA using 0.9\% tryptophan

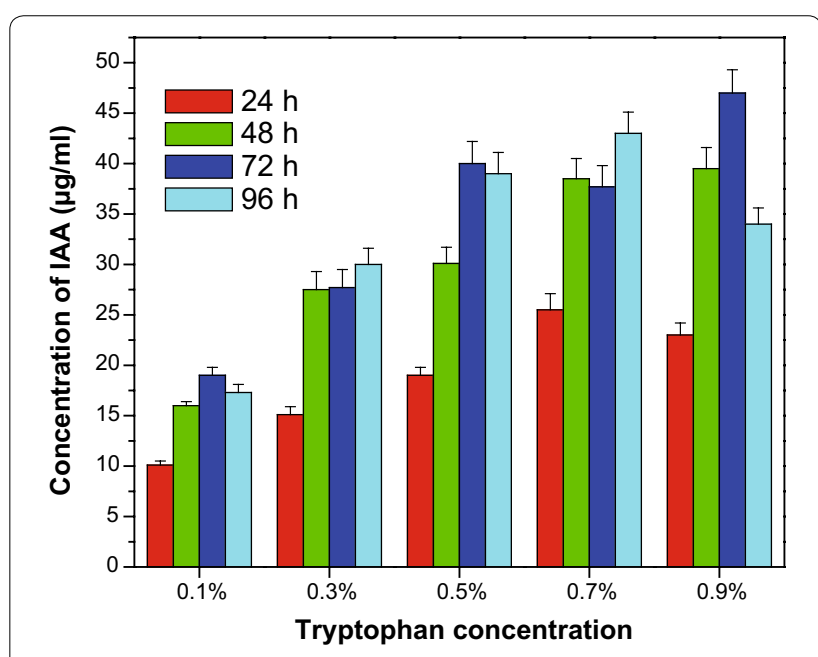

Fig. 2 Effect of tryptophan concentration on IAA production by $\mathrm{G} 2$

\section{Assessment of other plant growth promoting activities of the isolates \\ Hydrogen cyanide production}

On assessment of all the samples (F1 and G2) and (FC and GC) by Bakkers and Schippers method for detection of $\mathrm{HCN}$ production it was found that among the

isolates, strong brown color was observed in plate of F1 and no brown color was observed in G2 plate, whereas in consortiums, light brown color was observed in G2 plate. The difference of brown color formation of all the sample plates can be seen in figure given below. 
Table 2 Effects of $\mathrm{pH}$ on IAA production

\begin{tabular}{|c|c|c|c|c|c|}
\hline \multirow{2}{*}{$\begin{array}{l}\text { Culture } \\
\text { samples }\end{array}$} & \multirow[t]{2}{*}{$\mathrm{pH}$ range } & \multicolumn{4}{|c|}{ Concentration of IAA (in $\mu \mathrm{g} / \mathrm{ml}$ ) } \\
\hline & & $24 \mathrm{~h}$ & $48 \mathrm{~h}$ & $72 \mathrm{~h}$ & $96 \mathrm{~h}$ \\
\hline \multirow[t]{4}{*}{ F1 } & 5 & $0.9( \pm 0.1)$ & $3.6( \pm 0.4)$ & $1.4( \pm 0.2)$ & $1.1( \pm 0.1)$ \\
\hline & 7 & $7.3(0.4)$ & $10.1( \pm 0.5)$ & $0.9( \pm 0.1)$ & $8.1( \pm 0.4)$ \\
\hline & 9 & $15.2( \pm 0.8)$ & $13.1( \pm 0.5)$ & $12.6( \pm 0.5)$ & $0.9( \pm 0.1)$ \\
\hline & 11 & $0.5( \pm 0.1)$ & $5( \pm 0.4)$ & $0.9( \pm 0.1)$ & $1( \pm 0.1)$ \\
\hline \multirow[t]{4}{*}{ G2 } & 5 & $0.6( \pm 0.1)$ & $1.1( \pm 0.1)$ & $1.1( \pm 0.1)$ & $1.1( \pm 0.1)$ \\
\hline & 7 & $8.6( \pm 0.4)$ & $12( \pm 0.5)$ & $14.8( \pm 0.6)$ & $14.6( \pm 0.6)$ \\
\hline & 9 & $10.5( \pm 0.5)$ & $17.1( \pm 0.6)$ & $19.5( \pm 0.8)$ & $18.2( \pm 0.8)$ \\
\hline & 11 & $1.3( \pm 0.1)$ & $5.3( \pm 0.4)$ & $17.5( \pm 0.8)$ & $14.8( \pm 0.6)$ \\
\hline \multirow[t]{4}{*}{ FC } & 5 & $0.7( \pm 0.1)$ & $1.9( \pm 0.2)$ & $6.6( \pm 0.4)$ & $6.7( \pm 0.4)$ \\
\hline & 7 & $4.6( \pm 0.4)$ & $7.9( \pm 0.4)$ & $7.9( \pm 0.4)$ & $6.8( \pm 0.4)$ \\
\hline & 9 & $9.6( \pm 0.4)$ & $15.9( \pm 0.8)$ & $13.5( \pm 0.8)$ & $8.7( \pm 0.4)$ \\
\hline & 11 & $0.9( \pm 0.1)$ & $8.2( \pm 0.4)$ & $15.1( \pm 0.8)$ & $14.5( \pm 0.6)$ \\
\hline \multirow[t]{4}{*}{ GC } & 5 & $1.1( \pm 0.1)$ & $0.8( \pm 0.1)$ & $1.5( \pm 0.1)$ & $3.6( \pm 0.4)$ \\
\hline & 7 & $1( \pm 0.1)$ & $3.4( \pm 0.4)$ & $7( \pm 0.4)$ & $6.7( \pm 0.4)$ \\
\hline & 9 & $6.7( \pm 0.4)$ & $9.9( \pm 0.4)$ & $9.4( \pm 0.4)$ & $6.2( \pm 0.4)$ \\
\hline & 11 & $1.1( \pm 0.1)$ & $6.5( \pm 0.4)$ & $13.1( \pm 0.8)$ & $12.3( \pm 0.8)$ \\
\hline
\end{tabular}

Experiments were done in triplicates \pm SD

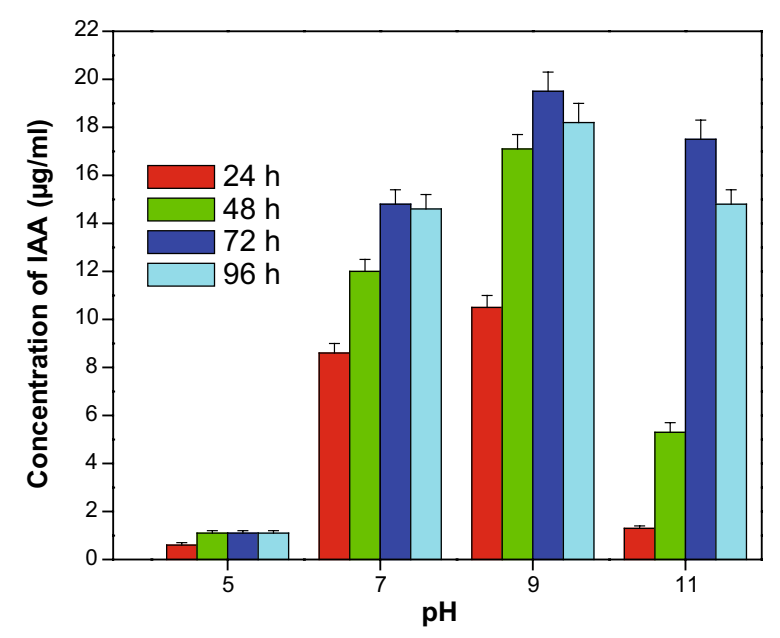

Fig. 3 Effect of $\mathrm{pH}$ on concentration of IAA produced by $\mathrm{G} 2$

\section{Oxalate solubilization}

After the incubation of samples on oxalic acid degradation selective medium for 7 days, no clear halos were observed around the bacterial spots inoculated on the plates. This indicated that none of the sample produced oxalate oxidase.

\section{Phosphate solubilization}

After the incubation of samples on Pikovskaya's agar for 2 days, zone of clearance was not observed around any of the bacterial spots inoculated on the plates. This indicated that none of the sample had phosphate solubilizing activity.

\section{Zinc solubilization}

The samples when incubated on Tris minimal media for 3 days, it was found that none of the samples were able to grow on the medium, which nullified the ability of zinc solubilization of the samples.

\section{Biochemical characteristics of the isolates}

On the basis of cultural, morphological and biochemical characteristics according to Bergey's Manual of Determinative Bacteriology (9th edition) it was found that F1 and G2 belongs to Micrococcus sp. and Pseudomonas sp. respectively.

Pot experiment 1: effect of IAA producer on plant growth All the plantlets grown in pots of both the batches supplied with their respective cultures showed varied growth pattern after a period of one month. It was seen that plants of Batch 1 showed better growth than Batch 2 . Among all the culture supplied pots, the pots supplied with isolates F1 and G2 showed better plant growth. The values of all parameters assessed for plant growth are given in Table 3.

\section{Cultivation of azolla}

On inoculation of $500 \mathrm{~g}$ azolla culture in pit a double yield was obtained, i.e., $1000 \mathrm{gm}$ in 15 days. The dried powder of azolla was taken for pot experiment 2 and field studies.

Pot experiment 2: effect of co inoculation of IAA producer and azolla on plant growth

All the plantlets grown in pots of this batch supplied with azolla powder and their respective cultures showed varied growth pattern after a period of one month. It was seen that plants of pot G2 showed better growth than all other pots of the batch. The values of all parameters assessed for plant growth of all the pots, are given in Table 4.

\section{Field study: effect of co inoculation of IAA producer and azolla on Seed Germination}

After one month, the plants grown in all four plots, viz Plot 1, Plot 2, Plot 3, and Plot 4 showed varied growth on assessment by different parameters given in Table 5 . It was found that, plants belong to Plot 1 and Plot 2 showed better plant growth.

\section{Discussion}

Soil is considered as the source of finding diverse kind of bacterial species, so the soil was considered as our priority for isolating IAA producers. Many researchers have 


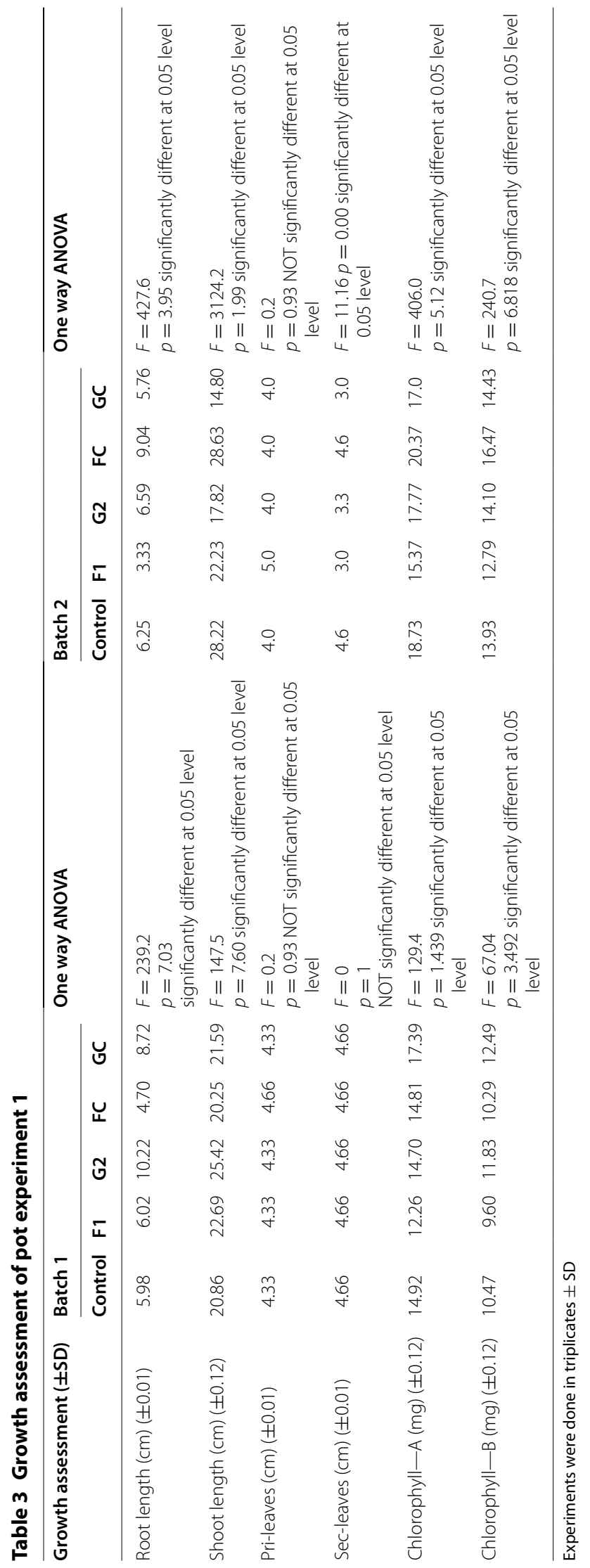


Table 4 Growth assessment of pot experiment 2

\begin{tabular}{|c|c|c|c|c|c|c|c|}
\hline \multirow[t]{2}{*}{ Growth assessment } & \multicolumn{6}{|c|}{ Sample cultures + Azolla } & \multirow[t]{2}{*}{ One way ANOVA } \\
\hline & Control & Azolla & F1 & G2 & $\mathrm{FC}$ & GC & \\
\hline Root length $(\mathrm{cm})( \pm 0.12)$ & 3.23 & 6.74 & 5.25 & 4.66 & 6.38 & 5.56 & $\begin{array}{l}F=153.33 \\
p=1.925 \text { significantly different at } 0.05 \text { level }\end{array}$ \\
\hline Shoot length $(\mathrm{cm})( \pm 0.12)$ & 28.51 & 31.02 & 31.5 & 36.32 & 27.18 & 36.48 & $\begin{array}{l}F=2492.28 \\
p=0 \text { significantly different at } 0.05 \text { level }\end{array}$ \\
\hline Pri-leaves $(\mathrm{cm})( \pm 0.01)$ & 7.33 & 8.66 & 8.66 & 10.66 & 6.33 & 7.33 & $\begin{array}{l}F=20.7 \\
p=1.60 \text { significantly different at } 0.05 \text { level }\end{array}$ \\
\hline Sec-leaves $(\mathrm{cm})( \pm 0.01)$ & 5.33 & 5.33 & 5 & 5.66 & 7.66 & 5.33 & $\begin{array}{l}F=10.28 \\
p=5.17 \text { significantly different at } 0.05 \text { level }\end{array}$ \\
\hline Chlorophyll—A(mg) ( \pm 0.12$)$ & 30.47 & 20.15 & 21.3 & 24.12 & 27.42 & 19.28 & $\begin{array}{l}F=3837.6984 \\
p=0 \text { significantly different at } 0.05 \text { level }\end{array}$ \\
\hline Chlorophyll—B(mg) ( \pm 0.12$)$ & 22.19 & 15.18 & 16.24 & 19.23 & 22.65 & 17.63 & $\begin{array}{l}F=3730.4 \\
p=0 \text { significantly different at } 0.05 \text { level }\end{array}$ \\
\hline
\end{tabular}

Experiments were done in triplicates \pm SD

Table 5 Field studies: effect of co inoculation of IAA producer and Azolla on seed germination

\begin{tabular}{llccc}
\hline Plant growth assessment & Plot $\mathbf{1}$ (control) & Plot 2 (only azolla) & Plot 3 (only culture) & Plot $\mathbf{4}$ (culture + Azolla) \\
\hline Root length (cm) & 5.42 & 5.58 & 3.95 & 3.05 \\
Shoot length (cm) & 14 & 14 & 15 & 15 \\
Primary leaves (cm) & 15 & 7 & 7 & 9 \\
Sec-leaves (cm) & 10 & 10 & 10 & 9 \\
Chlorophyll-A (mg) & 18.78 & 10.27 & 12.18 & 19.04 \\
Chlorophyll-B (mg) & 12.35 & 7.31 & 8.69 & 13.04 \\
\hline
\end{tabular}

used already isolated cultures or standard cultures for assessing the IAA production ability of it [24]. The traditional procedure of first isolating the rhizobial cultures and then screening them for IAA production was time consuming as, Sahasrabudhe [1] have isolated 60 cultures from rhizosphere of groundnut among them 40 cultures showed IAA production. Harikrishnan et al. [25] isolated 95 cultures of actinomycetes, out of 95, 65 isolates were found to be producing IAA. Taking in consideration the ability of soil samples to consist IAA producers, we have used soil samples for enrichment IAA producing microorganisms. Rather going for isolating the rhizospheric bacteria and then assessing the IAA producing ability of it, we have used a different way. We have enriched the soil samples directly in tryptophan containing medium and observed for pink coloration through Salkowski's test. This has reduced the long traditional procedure of isolating each bacteria and subsequent assessment of each one for IAA production. By this method we have found that $\mathrm{CS}$ does not have any bacteria with a potent IAA producing ability, whereas GS and FS soil samples contained maximum IAA producers (or bacteria with potent IAA producing ability).
The isolates which were obtained from GS $(\mathrm{G} 1, \mathrm{G} 2, \mathrm{G} 3, \mathrm{G} 4, \mathrm{G} 5)$ and FS (FS1,FS2,FS3,FS4,FS5) were separately assessed for their IAA producing ability. In addition to this a natural consortium of bacteria present in GS and FS was also maintained and named as GC and FC, respectively, and both these consortiums were also assessed for IAA producing ability. GC and FC were also used for further experiments along with F1 and G2. The reason behind using the isolates (F1 and G2) and consortiums (GC and FC) separately, was to use to different approaches, viz. "top down" and "bottom up" for getting the better IAA producer. In top down approach the natural consortium was used as it is for getting the better IAA producer and in bottom up approach each isolate was tested for getting better IAA producer. If the difference of IAA production between isolate and the consortiums would not have been statistically significant, we would have suggested to use the consortium rather than the isolates. This is because the natural consortium would be more stable in field conditions as compared to the isolates. But if we look at the results, the difference of IAA production between isolates and consortiums was statistically significant and it was found that $\mathrm{G} 2$ was better among them. 
The cultures were assessed for different parameters such as, effect of tryptophan concentration and $\mathrm{pH}$ on yield of IAA production and it was found that at $0.9 \%$ concentration of tryptophan the isolates F1 and G2 showed maximum production of IAA, i.e., $32.5 \mu \mathrm{g} / \mathrm{ml}$ and $47 \mu \mathrm{g} / \mathrm{ml}$ on incubation at $72 \mathrm{~h}$. The consortiums, FC and $\mathrm{GC}$ also performed well in IAA production at $0.9 \%$ concentration of tryptophan, i.e., $47.5 \mu \mathrm{g} / \mathrm{ml}$ and $26 \mu \mathrm{g} /$ $\mathrm{ml}$, but took $96 \mathrm{~h}$.

On different $\mathrm{pH}$ range, fluctuations in IAA productivity of all samples were observed, among the isolates F1 showed higher IAA production at pH 9, i.e., $15.2 \mu \mathrm{g} / \mathrm{ml}$ in $24 \mathrm{~h}$ and $\mathrm{G} 2$ produced maximum, i.e., $19.5 \mu \mathrm{g} / \mathrm{ml}$ IAA at pH 9 in $72 \mathrm{~h}$, whereas in case of consortiums, FC showed maximum IAA synthesis, i.e., $15.9 \mu \mathrm{g} / \mathrm{ml}$ at $\mathrm{pH} 9$ and GC showed maximum IAA, i.e., $13.1 \mu \mathrm{g} / \mathrm{ml}$. Thokal et al. [26] have also assessed the effect of $\mathrm{pH}$ values 4, 5, 6, 7 and 8 and they found $\mathrm{pH} 7$ as optimum for their cultures. Pantoea agglomerans produced maximum IAA production at $\mathrm{pH} 7$ [27].

On assessing all the samples for parameters such as, oxalate solubilization, zinc solubilization, $\mathrm{HCN}$ (hydrogen cyanide) production [20] and phosphate solubilization [22], it was found that in HCN production only the isolate F1 showed positive result, whereas all the samples were incapable of producing $\mathrm{HCN}$. For rest of the parameters, none of the sample culture was found to be potent. Ajay et al. [28] worked on the isolating, screening and characterization of bacteria from rhizospheric soils for different plant growth promoting activities, IAA production, phosphate solubilization, $\mathrm{HCN}$ production, siderophore production, ACC deaminase activity and catalase.

Though the IAA production ability of cultures was tested invitro, it was necessary to assess the same in practical conditions; hence the pot experiments were performed. The cultures were supplied at the vicinity of roots. This step was carried by assuming that there will be the dominance of microbes, present in supplied culture, in the competing environment of rhizosphere for nutrition.

Considering this, studies were carried in pot experiment 1 and it was found that, among the two sets, Set 1 consisting of sowing culture treated seeds showed better plant growth than Set 2, which consists of sowing untreated seeds with regular culture supply. The assessment of different growth parameters of plants from both the sets showed that, G2 is the superior isolate for plant growth. Though the other samples outperformed G2 in some parameters, G2 was found better for all the plant growth promoting abilities when taken as average. By observing this scenario, we can say that the reason of poor growth of set 2 may be due to the higher production of IAA which has posed a negative effect on plant growth. So further experiments were carried out by sowing pretreated seeds.

Pot experiment 2 was carried out with the aid of azolla. As azolla decomposes slowly in soil, it may provide a consistent limited supply of proteins and nutrients for the growth of rhizospheric bacteria [13]. Azolla could be a consistent provider of tryptophan (a precursor of IAA) for IAA producing microbe in rhizosphere. By assessing all growth parameters in pot experiment 2 it was found that G2 as an efficient plant growth promoting microorganism.

As we know many cultures which show good results in laboratory conditions or in controlled pot experimental conditions fails substantially when applied to natural conditions. The reason is compatibility and adaptability of cultures in such natural field conditions. So, considering this, it was decided to use a combination of G2 and Azolla on fields with suitable positive and negative controls. Among the four plots allotted for this experiment, on an average plot 2 (only azolla) and plot 4 (culture + azolla) showed efficient results in terms of plant growth assessment.

\section{Conclusions}

From the overall study, we can say that the isolate G2 is a potent IAA producer and an efficient plant growth promoter. Combined dose of G2 and dried azolla can be used as a good biofertilizer.

\section{Abbreviations \\ IAA: indole acetic acid; FC: farm soil consortium; GC: garden soil consortium; NB: nutrient broth; NA: nutrient agar; HCN: hydrogen cyanide; RT: room temperature.}

\section{Authors' contributions}

$\mathrm{RV}$ and SI developed the pot experiment and most of the laboratory analysis, interpretation of the results and manuscript writing. NB and PK offered advice during the development of the experiment, interpretation of the results. NA provided general conception and interpretation of results and manuscript writing. All authors read and approved the final manuscript.

\section{Author details}

${ }^{1}$ Department of Biotechnology, Badrinarayan Barwale College, Jalna, MS, India. ${ }^{2}$ Department of Microbiology, Badrinarayan Barwale College, Jalna, MS, India. ${ }^{3}$ Department of Chemistry, Badrinarayan Barwale College, Jalna, MS, India. ${ }^{4}$ Department of Biotechnology and Microbiology, Vivekanand Arts Sardar Dalipsingh Commerce and Science College, Aurangabad, MS, India.

${ }^{5}$ Dr. Babasaheb Ambedkar Marathwada University, Aurangabad, MS, India.

\section{Acknowledgements}

We are thankful to Mr. Sajid Shaikh Assistant professor New Arts Commerce and Science College Ahmednagar (M.S.) India for useful technical discussions related to work.

\section{Competing interests}

The authors declare that they have no competing interests.

\section{Funding}

No funding from any funding agency was received for carrying out this research work. 
Received: 15 September 2016 Accepted: 27 November 2016

Published online: 04 January 2017

\section{References}

1. Sahasrabudhe Madhuri M. Screening of rhizobia for indole acetic acid production. Ann Biol Res. 2011;2(4):460-8.

2. Ahmad F, Ahmad I, Khan MS. Screening of free-living rhizospheric bacteria for their multiple plant growth promoting activities. Microbiol Res. 2008;163(2):173-181. doi:10.1016/j.micres.2006.04.001.

3. Verma JP, Yadav J, Tiwari KN, Singh L, Singh V. Impact of plant growth promoting rhizobacteria on crop production. Int J Agri Res. 2010;5(11):954-83.

4. Elena S, Anton L, Birgitta B. Evidence for production of the phytohormone indole-3-acetic acid by cyanobacteria. Planta. 2002;215:229-38. doi:10.1007/s00425-002-0749-x

5. Varalakshmi P, Malliga P. Evidence for production of Indole-3-acetic acid from a fresh water cyanobacteria (Oscillatoria annae) on the growth of $\mathrm{H}$. annus. Int J Sci Res Publ. 2012:2(3):2250-3153.

6. Frankenberger WT Jr, Arshad M. Phytohormones in soils: microbial production and function. New York: Marcel Dekker, Inc; 1995. p. 5-40.

7. Arshad M. Frankenberger WT. Microbial production of plant hormones, Plant Soil. 1991:133:1. doi:10.1007/BF00011893.

8. Brown ME. Plant growth substances produced by microorganisms of soil and rhizosphere. J Appl Bacteriol. 1972:43:443-451.

9. Sarwar M, Frankenberger WT. Tryptophan dependent biosynthesis of auxins in soil. Plant Soil. 1994;160:97-104.

10. Barea JM, Brown ME. Effects on plant growth by Azotobacter paspali related to synthesis of plant growth regulating substances. J Appl Bacteriol. 1974:37:583-93.

11. Forni C, Riov J, GrillicCaiola M, Tel-Or E. Indole-3-acetic acid (IAA) production by Arthrobacter species isolated from Azolla. J Gen Microbiol. 1991;138:377-81.

12. Prasanna R, Jaiswal P, Nayak S, Sood A, Kaushik BD. Cyanobacterial diversity in the rhizosphere of rice and its ecological significance. Indian J Microbiol. 2008;49:89-97. doi:10.1007/s12088-009-0009-x.

13. Lumpkin TA, Plucknett DL. Azolla as a green manure: use and management in crop production. Westview Press, Boulder, Colorado; 1982.

14. Belnap J. 19 Factors influencing nitrogen fixation and nitrogen release in biological soil crusts. Ecol Stud, vol 150; 2001.

15. Wagner GM. Azolla: a review of its biology and utilisation. Bot Rev. 1997;63(1):1-26
16. Kamble KD, Galerao DK. Indole acetic acid production from Pseudomonas species isolated from rhizosphere of garden plants in Amravati. IJAPBC. 2015:4(1):2277-4688

17. Ahsan ML, Ali A, Ahmed I. Bio-fertilizer a highly potent alternative to chemical fertilizers: uses and future prospects. J Chem Eng Biol Sci. 2012;6(4):10-23.

18. Shahab Sadaf, Ahmed Nuzhat, Khan Nasreen S. Indole acetic acid production and enhanced plant growth promotion by indigenous PSBs. Afr J Agri Res. 2009:4(11):1312-6.

19. Khamna S, Yokota A, Lumyong S. Actinomycetes isolated from medicinal plant rhizosphere soils: diversity and screening of antifungal compounds, indole-3-acetic acid and siderophore production. World J Microbiol Biotechnol. 2008:25:649-55. doi:10.1007/s11274-008-9933-x.

20. Kumar P, Dubey RC, Maheshwari DK. Bacillus strains isolated from rhizosphere showed plant growth promoting and antagonistic activity against phytopathogens. Microbiol Res. 2012;167(8):493-9.

21. Dickman MB, Mitra A. Arabidopsis thaliana as a model for studying Sclerotinia sclerotiorum pathogenesis. Physiol Mol Plant Pathol. 1992:41:255-63.

22. Laslo E, Gyorgy E, Gyongyver M, Tamas E, Beata A, Szabolcs L. Screening of plant growth promoting rhizobacteria as potential microbial inoculants. Crop Prot. 2012;40:43-8.

23. Malboobi M, Owlia P, Behbahani M, Sarokhani E, Moradi S, Yakhchali B, Deljou A, Heravi KM. Solubilization of organic and inorganic phosphates by three highly efficient soil bacterial isolates. World J Microbiol Biotechnol. 2009:25:1471-7.

24. Sobral JK, Araújo WL, Mendes R, Geraldi IO, Pizzirani-Kleiner AA, Azevedo $J$. Isolation and characterization of soybean-associated bacteria and their potential for plant growth promotion. Environ Microbiol. 2004:6(12):1244-51.

25. Harikrishnan H, Shanmugaiah V, Balasubramanian N. Optimization for production of Indole acetic acid (IAA) by plant growth promoting Streptomyces sp VSMGT1014 isolated from rice rhizosphere. Int J Curr Microbiol Appl Sci. 2014;3(8):158-71.

26. Thokal PJ, Shelar BL, Shaikh SH, Adhapure NN. Microbial optimized production of indole acetic acid and assessment of other plant growth promoting activities. Int J Sci Nat. 2013;4(4):627-32.

27. Apine OA, Jadhav JP. Optimization of medium for indole-3-acetic acid production using Pantoea agglomerans strain PVM. J Appl Microbiol. 2011;110(5):1235

28. Ajay Kumar, Kumar Amit, Devi Shikha, Patil Sandip, Payal Chandani, Negi Sushila. Isolation, screening and characterization of bacteria from rhizospheric soils for different plant growth promotion (PGP) activities; an in vitro study. Recent Res Sci Technol. 2012;4(1):01-5.

\section{Submit your manuscript to a SpringerOpen ${ }^{\odot}$ journal and benefit from:}

- Convenient online submission

- Rigorous peer review

- Immediate publication on acceptance

- Open access: articles freely available online

- High visibility within the field

- Retaining the copyright to your article

Submit your next manuscript at springeropen.com 